\title{
Genetic and molecular analysis of the temperature- sensitive mutant un-17 carrying a mutation in the gene encoding poly(A)-polymerase in Neurospora crassa
}

\author{
Shuuitsu Tanaka*, Noriko Takayanagi, Kennichi Murasawa, Chizu Ishii \\ and Hirokazu Inoue \\ Laboratory of Genetics, Department of Regulation-Biology, Faculty of Science, Saitama \\ University, Shimo-ookubo 255, Sakura-ku, Saitama City 338-8570, Japan
}

(Received 13 September 2007, accepted 8 November 2007)

\begin{abstract}
The un-17 mutant was originally isolated as an irreparable temperature-sensitive (ts) mutant in Neurospora crassa. Early experiments showed that cells of this mutant immediately stopped growing and died when the temperature of the culture was shifted from a permissive temperature $\left(25^{\circ} \mathrm{C}\right)$ to non-permissive temperature $\left(35^{\circ} \mathrm{C}\right)$. This ts phenotype is suppressed by addition of cycloheximide or in some conditions of growth repression. Even at the permissive temperature, it shows a female sterile phenotype and is deficient in production of exocellular superoxide dismutase SOD4 (EC 1.15.1.1). By searching for a DNA fragment that complements the ts phenotype of the un-17 mutant from a $N$. crassa genome library, we found the un-17 gene. The cloned un-17 gene encodes a homolog of the Saccharomyces cerevisiae poly(A) polymerase (PAP). The un-17 mutant had a one-base substitution mutation in the gene. The cloned $u n-17$ genes from the wild-type strain and the un-17 mutant were introduced into both the un-17 mutant and wild-type strain. The un-17 mutant introduced by un-17 DNA from the wild-type strain showed recovery of both the ts and female sterile phenotypes. Moreover, the purified product derived from the wild-type strain showed PAP activity in vitro. These findings indicate that the un-17 mutant carries a ts mutation in the gene encoding PAP.
\end{abstract}

Key words: Neurospora, pleiotropic phenotype, poly(A) polymerase, ts mutant, un-17

\section{INTRODUCTION}

It is useful in analysis of essential genes to make use of conditional phenotypes such as temperature sensitivity. Beadle and Tatum first isolated temperaturesensitive (ts) mutants in Neurospora (1945), and Horowitz and Leupold suggested that the isolation of ts mutants might provide a special technique for detecting mutations in indispensable genes (1951). Inoue and Ishikawa isolated and characterized many ts mutants that showed growth defects at $35^{\circ} \mathrm{C}$ in Neurospora crassa (1970). Since functions of the mutated genes were "unknown", the prefix "un-" was used as the gene name. Several ungenes have been cloned and their functions have been confirmed (Onai et al., 1998; Smith et al., 2000; Sakai et

Edited by Akio Toh-e

* Corresponding author. E-mail: shtanaka@post.saitama-u.ac.jp al., 2002).

The phenotype of the un-17 mutant is particularly distinctive: it shows rapid and exponential cell death at $35^{\circ} \mathrm{C}$, which is suppressed by conditions inhibiting protein synthesis (Inoue and Ishikawa, 1970, 1975). At a restrictive temperature $\left(34^{\circ} \mathrm{C}\right)$, the $u n-17$ mutant accumulates the same phospholipid intermediates as those accumulated by the chol-2 mutant (Goodrich-Tanrikulu, personal communication). Munkres (1979) found that the un-17 mutant was also cold-sensitive and osmotic remedial. Moreover, several phenotypes in the un-17 mutant have been observed even at permissive temperatures. When it is used as a female parent, a few protoperithecia is produced (Perkins, unpublished). Also, it is deficient in exocellular superoxide dismutase, SOD4, activity (Munkres, 1992). We have been interested in the gene whose defect produces such a pleiotropic phenotype.

The gene encoding Poly(A) polymerase (PAP) which 
plays a role on processing of mRNA has been cloned from yeasts and various vertebrates, and their amino acid sequences predict it is a gene that has been highly conserved in evolution (Ohnacker et al., 1996). Yeast PAPs are encoded by the essential gene PAP1 for Saccharomyces cerevisiae and pla1 for Schizosaccharomyces pombe (Linger et al., 1991; Ohnacker et al., 1996). These two PAPs have $70 \%$ identity in amino acid sequences. In processing of mRNA, the 3'-ends of almost all eukaryotic mRNAs are generated by endonucleolytic cleavage of a primary transcript and subsequent polyadenylation of the upstream cleavage product (for reviews, Keller, 1995; Wahle, 1991). These steps are accomplished by a protein complex. In $S$. cerevisiae, four factors have been identified: cleavage factor I (CF I), CF II, polyadenylation factor (PF I), and PAP (Chen and Moore, 1992). Polyadenylation is specific in the presence of magnesium and to RNAs containing specific polyadenylation signal sequences. In the absence of PF I and CF I, PAP polyadenylates RNAs inefficiently and without substance specificity. It also appears that this unspecific activity is enhanced in the presence of manganese as a substitute for magnesium (Lingner et al., 1991; Chen and Moore, 1992).

In this study, we cloned a gene that complements the ts phenotype of the un-17 mutant and found that it is a homolog of PAP encoding gene. We found that the product of the un-17 gene cloned from the wild-type strain has PAP activity. The ts and female sterile phenotypes of the un-17 mutant were completely suppressed by transformation with the wild-type PAP-encoding gene. These findings suggest that the $u n-17$ gene encodes the functional PAP. The pleiotropic phenotypes of the un-17 mutant are discussed in the light of RNA processing.

\section{MATERIALS AND METHODS}

Strains and plasmids The $N$. crassa strain C1-T1037A (Tamaru and Inoue, 1989) was used as the wild-type strain. The un-17 strain (FGSC2356) described as TS25 (T51M171) in the previous paper (Inoue and Ishikawa, 1970) was used. For his-3 targeted transformation of $N$. crassa, a strain his-3A (FGSC6103) was used as a host. Escherichia coli strains DH5 $\alpha$, DH1 and XL1-Blue were used for amplification of plasmids and phages. The plasmid pBluescript $\mathrm{SK}^{+}$(Stratagene) was used for cloning of PCR products. The pFLAGN1 plasmid which was used as a vector for the his-3 targeted transformation carries the 5'-trancated his-3 gene of $N$. crassa, ccg-1 promoter for expression of an exogenous DNA in $N$. crassa, and ampicilin resistant gene $\left(\mathrm{Amp}^{\mathrm{r}}\right)$ for a selection marker in $E$. coli. (Kawabata et al., 2007).

Growth conditions, media and general genetic manipulation of $N$. crassa were as described by Davis and de Serres (1970). Crosses were performed on a synthetic crossing medium (Westergarrd and Mitchell, 1947). Phe- notype of progeny was identified with spot tests on sorbose medium (Schroeder, 1988).

DNA libraries and sib selection A genome library of wild-type $N$. crassa, constructed in the cosmid vector pMOcosX (Orbach and Sachs, 1991) was obtained from the Fungal Genetic Stock Center (FGSC, School of Biological Sciences, University of Missouri, Kansas City, MO). We identified cosmids which complimented the ts phenotype of the un-17 mutant according to sib-selection method described by Tomita et al. (1993). Briefly, DNA solution which contained multiple cosmids' DNA was used to transform the $u n-17$ germinating conidia treated with Novozyme ${ }^{\mathrm{TM}}$ (Novozyms, Inc.). After transformation, spheroplasts were embedded in a sorbitol medium and incubated overnight at $25^{\circ} \mathrm{C}$. Then, the temperature was changed to $35^{\circ} \mathrm{C}$ for the test of temperature sensitivity.

Molecular cloning and sequencing Standard molecular techniques were carried out according to Sambrook et al. (1989). The sequence data of a putative PAPencoding gene (NCU08983.2) of $N$. crassa was obtained from the $N$. crassa genome database (Whitehead Institute, MIT Center for Genome Research). N. crassa genomic DNA was prepared from mycelia using a procedure described by Irelan et al. (1993). A high-fidelity Taq (Expand ${ }^{\mathrm{TM}}$ High-Fidelity PCR system, Roche Diagnostics Corp.) was used for amplification of DNA by PCR, following the protocol of the manufacturer. A DNA fragment encoding the putative PAP of either the wild-type strain or the un-17 mutant was amplified by PCR from their genomic DNAs using the following two primers: XbaI-PAP-5' (5'-GCGCTTCTAGACACCATGTCG-3') and SacI-PAP-3' (5'-GTCTGGAGCTCCTTCGATCAG-3'). The PCR products were integrated into the pBluescript $\mathrm{SK}^{+}$. DNA sequencing was achieved using the PLISM sequencer (ABI).

\section{Synthesis and purification of FLAG-tagged PAPs} A vector which contains 3 repeats of FLAG sequences (3 $\times$ FLAG) at a downstream of $c c g-1$ (formerly grg-1, McNally and Free, 1988) promoter of pMF272 (Falco et al., 2003) was named as pFLAGN1 (Kawabata et al., 2007). DNA fragments of the $u n-17$ gene from the wildtype strain and the $u n-17$ mutant were amplified from the genomic DNAs using the following two primers: SmaIh3PAP-5' (5'-CTTCGCCCGGGCATGTCGAA-3') and ApaIh3PAP-3' (5'-GTCTGTGGGCCCTTCGATCAG-3'). The PCR products were integrated into the pFLAGN1 at the downstream of ccg-1 promoter with the $3 \times$ FLAG sequence. In this step, the GFP gene of pFLAGN1 was excluded. The obtained plasmid was used to transform the $N$. crassa his-3 strain after digestion with Dra I. For introduction of exogenous DNA into recipient cells, an 
electroporation method was used (Ninomiya et al., 2004). After transformation, histidine prototroph colonies were isolated and homokaryotic strains were obtained through several cycles of single colony isolation.

FLAG-tagged proteins were purified from mycelia by immunoprecipitation using resins conjugated anti-FLAG antiserum as described (Kawabata et al., 2007). In brief, mycelia obtained after incubation of conidia in a minimal medium for $6 \mathrm{hrs}$ were corrected and frozen with liquid $\mathrm{N}_{2}$. Frozen mycelia were broken by Micro-smash (about $1,000 \times \mathrm{G}, 1 \mathrm{~min} \times 3$ times with interval on ice, Tomy) in IBF buffer containing protease inhibitors (inhibitor cocktail, Roche Diagnostics Corp.) with quarts sands. The mixture was centrifuged (about $16,000 \times \mathrm{G}, 10 \mathrm{~min}, 4^{\circ} \mathrm{C}$ ), and the supernatant was corrected into a new tube. With several round of this purification, the supernatant was used as cell lysate for immunoprecipitation of FLAGtagged proteins. The cell lysate $(0.05 \mathrm{ml})$ was gentry mixed with resins conjugated anti-FLAG antiserum (10 $\mu \mathrm{l}$, anti-FLAG M2 affinity agarose, Sigma) in IBF ( $0.5 \mathrm{ml}$ ) for $1.5 \mathrm{hr}$ at $4^{\circ} \mathrm{C}$. After the resin was washed with IBF several times, bound proteins were extracted from the resin by incubation at $4^{\circ} \mathrm{C}$ for 30 min with IBF buffer $(0.05 \mathrm{ml})$ containing FLAG peptide $(0.1 \mathrm{mg} / \mathrm{ml}, 3 \times \mathrm{FLAG}$, Sigma). Protein concentration of the extract was determined by BCA protein assay kit (PIERCE) using albumin as a standard. For ascertain of the purity, the extract was separated on a $10 \%$ SDS-polyacrylamide gel and then transferred to a polyvinylidene difluoride membrane (PVDF: Millipore). Detection of FLAG-tagged proteins was performed with an enhanced chemoluminescence detection kit (ECL: Amersham) according to the manufacturer's direction, with a primary antiserum (anti-FLAG: 1/2500, mouse-IgG, anti-FLAG M2 monoclonal antibody, Sigma) and a secondary antiserum (anti-mouse: $1 / 2500$, goat-IgG, anti-mouse-HRP conjugate, Promega) after blocking with BSA (5\%, Thermo) in TBS-T.

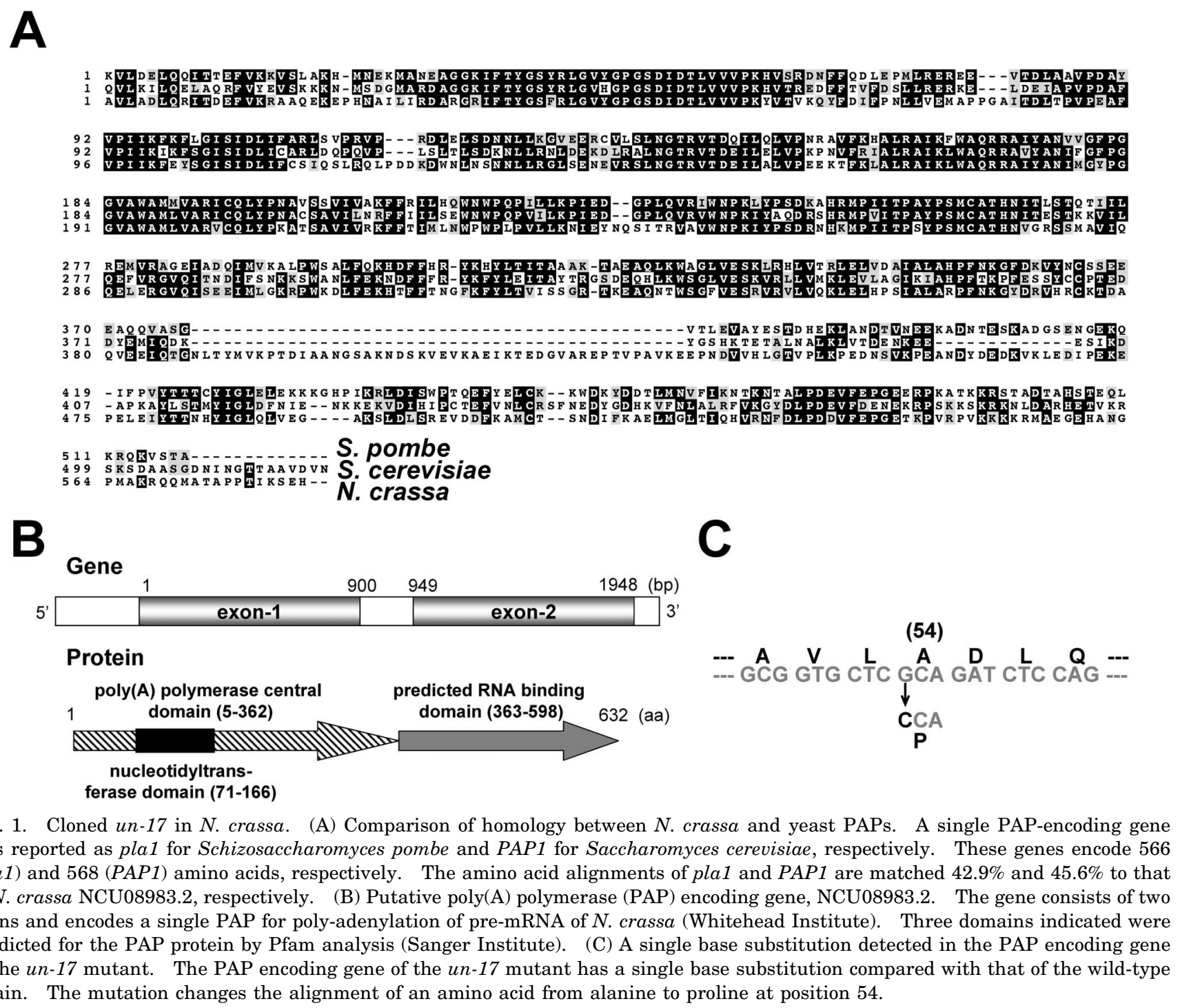

Fig. 1. Cloned un-17 in N. crassa. (A) Comparison of homology between N. crassa and yeast PAPs. A single PAP-encoding gene was reported as pla1 for Schizosaccharomyces pombe and PAP1 for Saccharomyces cerevisiae, respectively. These genes encode 566 (pla1) and 568 (PAP1) amino acids, respectively. The amino acid alignments of pla1 and PAP1 are matched $42.9 \%$ and $45.6 \%$ to that of N. crassa NCU08983.2, respectively. (B) Putative poly(A) polymerase (PAP) encoding gene, NCU08983.2. The gene consists of two exons and encodes a single PAP for poly-adenylation of pre-mRNA of $N$. crassa (Whitehead Institute). Three domains indicated were predicted for the PAP protein by Pfam analysis (Sanger Institute). (C) A single base substitution detected in the PAP encoding gene of the un-17 mutant. The PAP encoding gene of the un-17 mutant has a single base substitution compared with that of the wild-type strain. The mutation changes the alignment of an amino acid from alanine to proline at position 54 . 
Growth assay Conidia of the each strain were collected, and suspended with $0.075 \mathrm{M}$ phosphate buffer $(\mathrm{pH}$ 7.0) after washing two times. The suspension was diluted to a concentration of $2 \times 10^{6}$ conidia / ml. To obtain different concentration of conidial suspension, the suspension was stepwise diluted three times to one / fifth. Ten $\mu$ l of these four serial suspensions was spotted onto agar plates of minimal medium containing sorbose and histidine. After incubation under each condition $\left(15,25,37^{\circ} \mathrm{C}\right.$, or in the presence of $300 \mu \mathrm{M}$ paraquat) for 2-3 days, each plate was photographed.

in vitro PAP assay PAP activity was detected by nonspecific PAP assay as described (Nagaike et al., 2005) with some modifications. The assay was carried out either $25^{\circ} \mathrm{C}$ or $35^{\circ} \mathrm{C}$ for $30 \mathrm{~min}$ in reaction mixtures (final $10 \mu \mathrm{l}$ ) containing $50 \mathrm{mM}$ Tris- $\mathrm{HCl}\left(\mathrm{pH} \mathrm{8.0)}, 10 \mathrm{mM} \mathrm{MgCl}_{2}\right.$, $2.5 \mathrm{mM} \mathrm{MnCl}_{2}, 40 \mathrm{mM} \mathrm{KCl}, 0.2 \mathrm{mg} / \mathrm{ml} \mathrm{BSA}, 10 \%$ glycerol, $0.1 \mathrm{mM}$ ATP, $0.033 \mu \mathrm{M}\left[\alpha_{-}{ }^{32} \mathrm{P}\right]$ ATP (61-32007X, MP Bio), $1 \mathrm{mM}$ ditiothreitol, $100 \mu \mathrm{M}$ oligo(A) $)_{12}$ (System Science), and 1-2 $\mu \mathrm{g}$ of purified protein. After the reaction, 100 mM ATP was immediately added into the mixture, and the mixture was kept on ice. After adding of $40 \mu$ dye (90\% formamide, $0.3 \% \mathrm{BPB}$, and $20 \mathrm{mM}$ EDTA), the mixture was heated at $70^{\circ} \mathrm{C}$ for $5 \mathrm{~min}$. Then the mixture was subjected to electrophoresis on a denaturing polyacrylamide gel (15\%) containing $7 \mathrm{M}$ urea (length, $45 \mathrm{~cm}$; thickness, $0.1 \mathrm{~mm}$ ). After drying, the gel was exposed to an imaging plate, and the radioactivity was analyzed by an imaging analyzer BAS 3000 (Fuji Film).

\section{RESULTS}

Cloning of the un-17gene The un-17 mutation is located between $\operatorname{trp}-1(4 \%)$ and $T(U K 8-18)^{R}$ and is linked to nit-7 (0/63) at linkage group III R (Perkins et al., 2001). We searched for DNA fragments that complemented the ts phenotype of the un-17 mutant by transformation with DNA from a $N$. crassa genome library. Using a sib-selection method, one cosmid clone (clone number X9:E10) that was able to maintain growth of the $u n-17$ mutant after a change in temperature to $35^{\circ} \mathrm{C}$ was identified. After sub-cloning of the DNA fragments that were derived from the cosmid digested with Eco RI and Hind III, a fragment of about $6.5 \mathrm{kbp}$ in length that complemented the ts phenotype was obtained. Partial sequencing of the fragment showed that it contained the full length of a hypothetical gene, NCU08983.2, that encodes a homolog of yeast poly(A) polymerase (PAP) (Fig. 1A, B). Because NCU08983.2 is localized at number 67 contig on the physical map of $N$. crassa, the position is closed to that on the genetic map.

Since the PAP-encoding genes in both $S$. cerevisiae and S. pombe are essential (Lingner et al., 1991; Ohnacker et al., 1996) (Fig. 1A), the Neurospora PAP-encoding gene is a possible candidate to cause a conditional phenotype found in the un-17 mutant. To confirm this, the putative PAP-encoding genes were amplified by PCR from the un-17 mutant and the wild-type strain and cloned into a vector pBluescript as described in M \& M. Sequencing of the full lengths of these DNA fragments (about $2 \mathrm{kbp}$ ) revealed that there is a single base difference on the putative PAP-encoding region between the wild-type strain and the un-17 mutant, resulting in an amino acid substitution of Ala to Pro at 54 in PAP polypeptide (Fig. 1C).

Forced expression of the FLAG-tagged PAP-encoding genes To know the effect of the mutant PAP-encoding

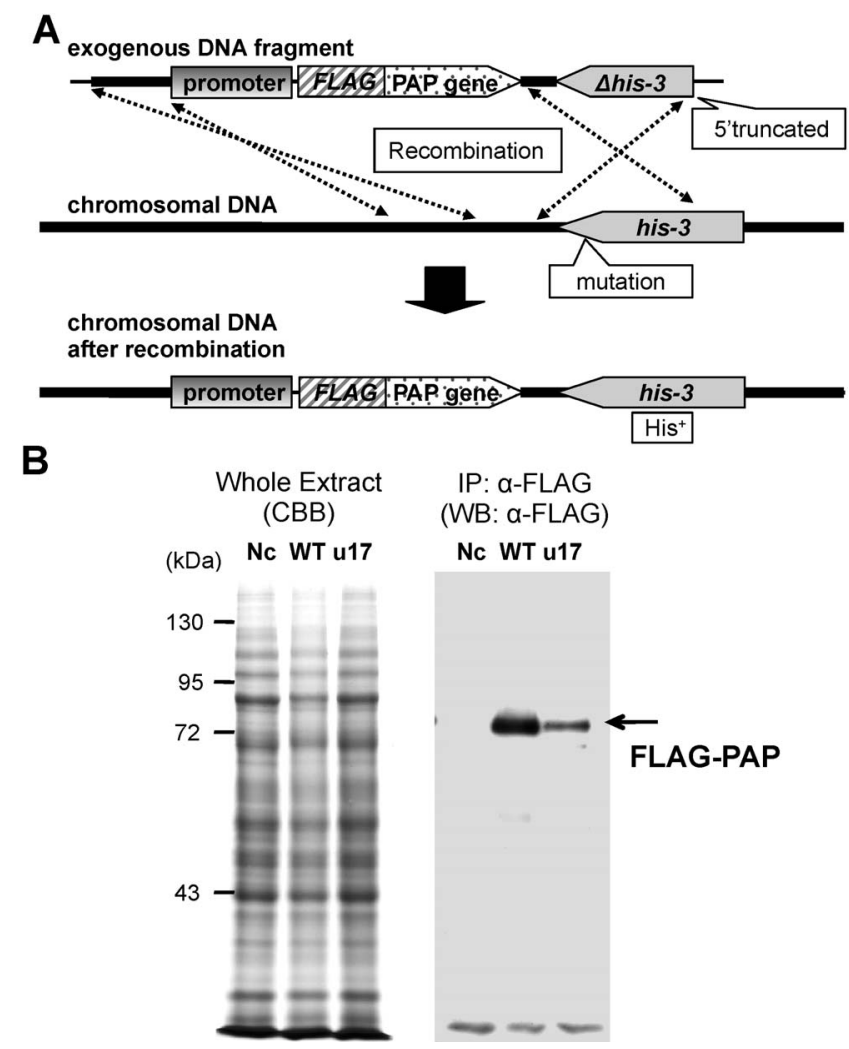

Fig. 2. Forced expression of the FLAG-tagged PAP-encoding genes. (A) Gene replacement at the his-3 locus. A sequence of the FLAG-tagged PAP-encoding gene was inserted downstream of the $c c g-1$ promoter of pFLAGN1 vector containing a 5'truncated sequence of the his-3 gene. A digested DNA fragment of it was introduced into conidia obtained from the his-3 mutant by electroporation and injected to the his-3 locus by double homologous recombinations. The $\mathrm{His}^{+}$strain was selected as a recombinant. (B) Detection of the FLAG-tagged PAP protein. Whole protein extracts were obtained from mycelia of each strain: negative control (Nc), obtained from a wild-type strain; WT, obtained from a strain transformed with the FLAG-tagged wildtype PAP-encoding gene; u17, obtained from a strain transformed with the FLAG-tagged un-17 PAP-encoding gene. Extracts were separated by PAGE and stained with coomassie brilliant blue (CBB, left panel). The FLAG-tagged PAP was purified by immunoprecipitation (IP) using anti-FLAG antiserum, and a part of it (about $10 \mu \mathrm{g}$ ) was separated by PAGE and detected by Western blotting (WB) using anti-FLAG antiserum (right panel). 


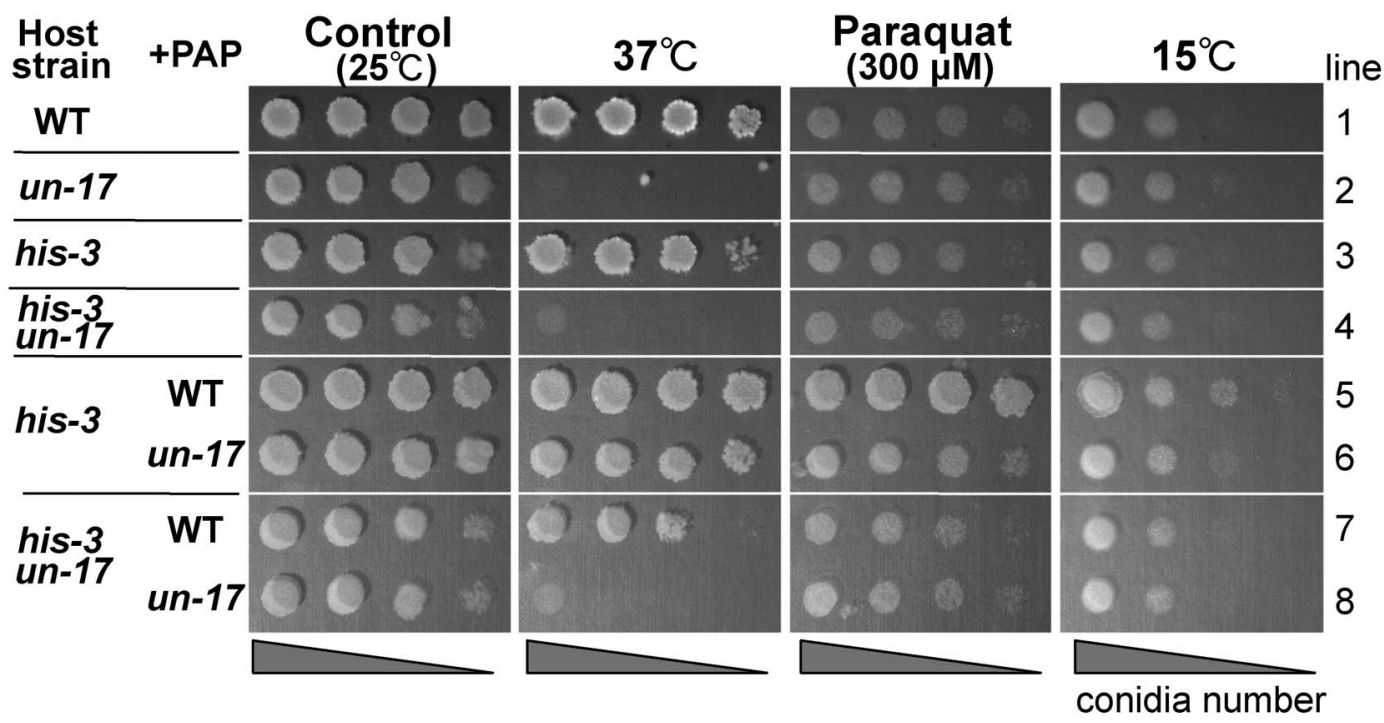

Fig. 3. Effects of forced expression of the PAP encoding genes on growth of the wild-type strain or the un-17 mutant. The his-3 single and his-3 un-17 double mutants were transformed with the wild-type (WT) or un-17 (un-17) PAP-encoding gene. Conidia suspensions $\left(2 \times 10^{4}, 4 \times 10^{3}, 8 \times 10^{2}\right.$, and $1.6 \times 10^{2}$ per $\left.10 \mu \mathrm{l}\right)$ of each strain were spotted onto agar plates containing histidine $(0.1 \mathrm{mg} / \mathrm{ml})$ in the presence or absence of paraquat $(300 \mu \mathrm{M})$. The plates were incubated at $25^{\circ} \mathrm{C}$ (plates for Control and Paraquat), at $15^{\circ} \mathrm{C}$ for 3 days or at $37^{\circ} \mathrm{C}$ for 2 days and photographed. Note that transformed strains had been changed to prototroph comparing host strains is not.

gene, we constructed strains expressing either wild-type un-17 or the mutant un-17. Targeting of manipulated genes to the his-3 locus is the most frequently used method for locus targeting gene integration in Neurospora (Aramayo and Metzenberg, 1996; Margolin et al., 1997). Our scheme for the replacement of the his-3 gene via a double crossover is shown in Fig. 2A. Neurospora transformants with this construct are expected to synthesize the FLAG-tagged PAP constitutively. The vector was introduced into the his-3 mutant by electroporation, and prototroph that is histidine-nonrequiring was isolated as a transformant. After several times of single colony isolation, we constructed a homokaryotic strain. Synthesis of FLAG-tagged PAP in the homokaryotic cells was confirmed by immunoprecipitation and Western blotting with anti-FLAG antiserum (Fig. 2B). The un-17 mutant PAP was detected at the same position as the wild-type PAP in Western blotting, but the amount of it was lower than that of the wild-type PAP (Fig. 2B, right).

Effects of forced expression of the PAP-encoding genes on the phenotypes of wild-type strain or un-17 mutant The un-17 mutant shows a pleiotropic phenotype: heat sensitivity (Inoue and Ishikawa, 1970), female sterility (Perkins, unpublished), altered phospholipid synthesis (Goodrich-Tanrikulu, personal communication), cold sensitivity (Munkres, 1979), and deficiency of exocellular SOD, SOD4, activity (Munkres, 1992). We examined whether the forced expression of putative PAPencoding genes affected phenotypes of either the wildtype strain or the un-17mutant. The un-17 mutant synthesizing the FLAG-tagged wild-type PAP grew at $37^{\circ} \mathrm{C}$, though the original un-17 mutant did not germinate and grow at $37^{\circ} \mathrm{C}$ (Fig. 3). However, we could not examine the effect of the extra PAP on cold sensitivity and SOD activity because we could not detect a significant difference in growth at $15^{\circ} \mathrm{C}$ or in growth under the condition of a highly reactive oxygen-stress (paraquat) between the wild-type strain and the original un-17mutant (lane 1 versus lane 2). On the other hand, we detected a growthpromotive effect of over-expression of the wild-type PAPencoding gene. In the case of transformation of the his-3 strain, but not the his-3 un-17 double mutant, growth of

\section{The un-17 mutant transformed to synthesize WT-PAP un-17-PAP}



Fig. 4. Recovery of female fertility of the un-17 mutant by forced expression of the wild-type PAP-encoding gene. Conidia obtained from the un-17 strain transformed with the wild-type or un-17 PAP-encoding gene were dispersed onto a nitrogenstarved agar medium for formation of protoperithecia. After incubation for one week, conidia of the wild-type strain were added for fertilization. Perithecia that formed (black dots) were photographed after about three weeks. Bar indicates $1 \mathrm{~cm}$. 
the his $-3^{+}$strain in which the wild-type PAP-encoding gene was introduced was better than that of the his $-3^{+}$ strain in which the un-17 PAP-encoding gene was introduced in the presence of paraquat or at a low temperature (lane 5 versus lane 6).

Fertility of the transformed un-17 strain in which the wild-type PAP-encoding gene had been introduced was examined. As shown in Fig. 4, the transformed un-17 strain in which the wild-type PAP-encoding gene had been introduced produced many protoperithecia, and those protoperithecia developed into mature perithecia when they were fertilized with the wild-type strain. The un-17 transformant introduced by the un-17 PAP-encoding gene produced a few protoperithecia like the described phenotype of the original un-17 mutant. This result indicates
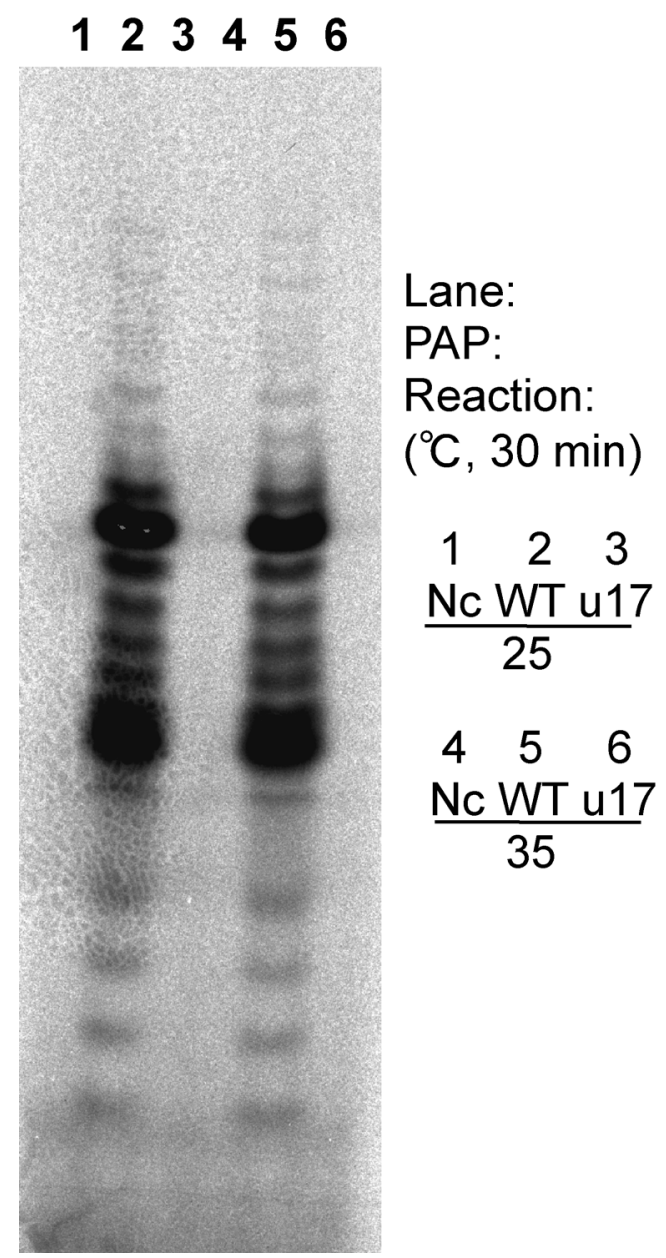

Fig. 5. Detection of PAP activity. Purified FLAG-tagged PAPs (negative control, Nc, obtained from the wild-type strain; WT, obtained from the $h i s-3^{+}$strain transformed with the wild-type PAP-encoding gene; $\mathrm{u} 17$, obtained from the $h i s-3^{+}$strain transformed with the un-17 PAP-encoding gene) (1-2 $\mu \mathrm{g})$ were added to reaction mixtures for assay of non-specific PAP reaction and incubated at 25 or $35^{\circ} \mathrm{C}$ for $30 \mathrm{~min}$. In this assay, reaction products were obtained as a result of polymerization of $\left[\alpha-{ }^{32} \mathrm{P}\right]$ ATP at the 3'-end of oligo(A) $)_{12}$. These products were separated on a denatured polyacrylamide gel and autoradiographed. that female fertility of the un-17 mutant was recovered by synthesis of the wild-type PAP. We also examined morphology of ascospores derived from a cross of the un-17 mutant into which the wild-type PAP-encoding gene had been introduced with the wild-type strain. The sizes of the ascospores were normal, but many of them were white, suggesting that both endogenous and transformed PAP-encoding genes were disrupted by repeat-induced point mutation (RIP, Selker et al., 1987) (data not shown).

PAP assay To determine whether the un-17 phenotype is derived from the imperfect PAP activity, we examined the activity of the wild-type PAP and the un-17 mutant PAP. Both of the FLAG-tagged PAPs were purified immunologically and used for assay of non-specific PAP activity (Zhelkovsky et al., 1995; Haracska et al., 2005; Nagaike et al., 2005). In this assay, PAP activity was measured as polymerization of $\left[\alpha_{-}{ }^{32} \mathrm{P}\right]$ ATP to the 3'-end of oligo(A). Figure 5 shows PAP activity of the wild-type and $u n-17$ PAPs. The wild-type PAP showed an apparent activity at both $25^{\circ} \mathrm{C}$ and $35^{\circ} \mathrm{C}$, indicating that $N$. crassa NCU08983.2 encodes a functional PAP. However, the activity of PAP was not detected for the un-17 PAP at $35^{\circ} \mathrm{C}$ and even at the permissive temperature, $25^{\circ} \mathrm{C}$.

\section{DISCUSSION}

We have shown that the mutation of the $u n-17$ mutant is a single base substitution in the PAP-encoding gene of $N$. crassa and that the both ts and female sterile phenotypes of the mutant were completely recovered by expression of the introduced wild-type PAP-encoding gene. We have also shown that the isolated PAP protein has PAP activity in vitro.

Forced expression of the wild-type PAP-encoding gene in the un-17 mutant resulted in complete recovery of the growth at $35^{\circ} \mathrm{C}$ and female fertility. This observation strongly suggests that the phenotypes of the un-17 mutant resulted from the mutated PAP-encoding gene. Concerning both the cold sensitivity and the paraquat sensitivity of the un-17 mutant, we could not detect a significant difference between the wild-type strain and the un-17 mutant. On the other hand, apparent resistance against oxidant stress was induced by over-expression of the wild-type PAP-encoding gene (Fig. 3, lane 5). In this strain, both the endogenous and introduced wild-type PAPs are thought to work additively in mRNA processing. The total amount of wild-type PAP may affect the viability of the cell. In any case, it is impossible to determine whether the expression of the wild-type PAP-encoding gene results in recovery of these sensitivities in our experimental conditions. Since the RNA-binding domain of the un-17 PAP is normal, the mutant PAP is thought to be able to bind transcribed pre-mRNAs as well as the wild-type PAP. The two PAPs may compete to bind pre- 
mRNAs. Except for growth under restricted temperature and protoperithecia formation, we could not detect any effect of either the expression of the un-17 PAPencoding gene in the wild-type strain or the expression of the wild-type PAP-encoding gene in the un-17 mutant (Figs. 2, 3, and unpublished). These data suggest that at the permissive temperature, the un-17 PAP has minimal, but sufficient, activity to maintain normal vegetative growth.

Since the un-17 mutant shows the ts phenotype, the un$17 \mathrm{PAP}$ is thought to have PAP activity at the permissive temperature in vivo. However, we could not detect PAP activity of the mutant PAP even at the permissive temperature $\left(25^{\circ} \mathrm{C}\right)$ in vitro. Alignment analysis of the amino acid sequence indicates that the PAP protein of $N$. crassa has both the PAP central domain containing the nucleotidyltransferase domain and the predicted RNAbinding domain, as do PAPs of other organisms (Fig. 1 B). The mutation (A54P) of the un-17 strain is localized between the N-terminal region and the nucleotidyltransferase domain. It is known that PAP needs several protein factors for the accurate modification of mRNA: CF I and PF I for yeast PAP (Chen and Moore, 1992) and CPSF for bovine PAP (Bienroth et al., 1993). Zhelkovsky et al. (1995) showed that for S. cerevisiae PAP, elimination of 16 amino acids from the amino-terminal end had no effect on the nonspecific activity of PAP but that elimination of the first 44 amino acids made the enzyme completely inactive. They speculated that there is a novel domain near the N-terminal region of PAP that is necessary for protein-protein interactions. The substitution of alanine to proline may have an influence on the interaction of PAP with these modulating proteins. This idea suggests that the mutant un-17 PAP may show PAP activity only in the presence of specific factors at the permissive temperature in vitro (Zhelkovsky et al., 1995; Ohnacker et al., 1996).

The phenotype of the un-17 mutant may result from the instability of mutated PAP as well as from the defective activity of the protein. The A54P substitution of the PAP polypeptide may induce an unstable structure of the protein. Since either the FLAG-tagged wild-type or un-17 PAP-encoding gene was introduced in the his-3 strain, the amounts of FLAG-tagged PAP synthesized were expected to be equal. Although we could not detect any degraded product of the FLAG-tagged un-17 PAP by Western blotting, the amount of purified un-17 PAP polypeptide was less than that of the wild-type PAP (Fig. 2B, right).

If the un-17 PAP changes the ability to interact with other factors for the accurate modification of mRNA as described above, there is also the possibility that the mutant PAP make shorter the length of poly(A) tails of mRNAs. The poly(A) tail plays roles in both stability and translocation into the cytoplasm of mRNA. There are several reports about the connection of the length of
poly(A) tails with mRNA stability (Shapiro et al., 1988; Herrick et al., 1990; Nie et al., 2004). Also, the poly(A) tail provides a binding site for poly(A)-binding proteins (PABPs: for review, Mangus et al., 2003). Although they lack catalytic activity, PABPs have several roles in mediating gene expression. Nuclear PABPs regulate the ultimate length of the poly(A) tail and stimulate maturation of the mRNA. Association with PABP is also a requirement for some mRNAs to be exported from the nucleus. In the cytoplasm, PABPs facilitate the formation of the closed loop structure of the messenger ribonucleoprotein particle that is crucial for additional PABP activities that promote translation initiation and termination, recycling of ribosomes, and stability of the mRNA. Results of these previous studies indicate that the stability of each mRNA is determined specifically by several factors which affect to each mRNA. For this reason, the un-17 mutant might have multiple phenotypes. As a test, several mRNAs were examined by Northern blotting. We could not detect any changes in either the length or the amount of translation elongation factor (tef)-1, $\beta$-tubulin (Bml), and cytoplasmic ribosomal protein (crp)-7 mRNAs between the wild-type and un-17 strains even under a restrictive condition (data not shown).

Our results suggest that the $u n-17$ gene encodes an essential gene for PAP and that a mutant of the gene shows pleiotrophy.

\section{REFERENCES}

Aramayo, R., and Metzenberg, R. L. (1996) Gene replacements at the his-3 locus of Neurospora crassa. Fungal Genet. Newsl. 43, 9-13.

Beadle, G. W., and Tatum, E. L. (1945) Neurospora II. Methods of producing and detecting mutations concerned with nutritional requirements. Am. J. Bot. 32, 678-686.

Bienroth, S., Keller, W., and Wahle, E. (1993) Assembly of a processive messenger RNA polyadenylation complex. EMBO J. 12, 585-594.

Chen, J., and Moore, C. (1992) Separation of factors required for cleavage and polyadenylation of yeast pre-mRNA. Mol. Cell Biol. 12, 3470-3481.

Davis, R. H., and de Serres, F. J. (1970) Genetic and microbiological research techniques for Neurospora crassa. Methods Enzymol. 17, 79-143.

Folco, H. D., Freitag, M., Ramón, A., Temporini, E. D., Alvarez, M. E., García, I., Scazzocchio, C., Selker, E. U., and Rosa, A. L. (2003) Histone H1 is required for proper regulation of pyruvate decarboxylase gene expression in Neurospora crassa. Eukaryot. Cell 2, 341-350.

Haracska, L., Johnson, R. E., Prakash, L., and Prakash, S. (2005) Trf4 and Trf5 proteins of Saccharomyces cerevisiae exhibit poly(A) RNA polymerase activity but no DNA polymerase activity. Mol. Cell Biol. 25, 10183-10189.

Herrick, D., Parker, R., and Jacobson, A. (1990) Identification and comparison of stable and unstable mRNAs in Saccharomyces cerevisiae. Mol. Cell Biol. 10, 2269-2284.

Horowitz, N. H., and Leupold, U. (1951) Some recent studies bearing on the one gene-one enzyme hypothesis. Cold Spring Harbor Symp. Quant. Biol. 16, 65-74. 
Inoue, H., and Ishikawa, T. (1970) Macromolecule synthesis and germination of conidia in temperature-sensitive mutants of Neurospora crassa. Jpn. J. Genet. 45, 357-369.

Inoue, H., and Ishikawa, T. (1975) Death resulting from unbalanced growth in a temperature-sensitive mutant of Neurospora crassa. Arch. Microbiol. 104, 1-6.

Irelan, J., Miao, V., and Selker, E. U. (1993) Small scale DNA preps for Neurospora crassa. Fungal Genet. Newsl. 40, 24.

Kawabata, T, Kato, A., Suzuki, K., and Inoue, H. (2007) Dysfunction of Neurospora crassa mus-41 (yeast RAD5 homolog) results in higher sensitivity to mutagens but has little effect on PCNA-ubiquitylation in response to UV-irradiation. Curr. Genet. 52, 125-135.

Keller, W. (1995) No end yet to messenger RNA 3' processing! Cell 81, 829-832.

Lingner, J., Kellermann, J., and Keller, W. (1991) Cloning and expression of the essential gene for poly(A) polymerase from S. cerevisiae. Nature 354, 496-498.

Mangus, D. A., Evans, M. C., and Jacobson, A. (2003) Poly(A)binding proteins: multifunctional scaffolds for the posttranscriptional control of gene expression. Genome Biol. 4, 223.

Margolin, B. S., Freitag, M., and Selker, E. U. (1997) Improved plasmids for gene targeting at the his-3 locus of Neurospora crassa by electroporation. Fungal Genet. Newsl. 44, 34-36.

McNally, M. T., and Free, S. J. (1988) Isolation and characterization of a Neurospora glucose-repressible gene. Curr. Genet. 14, 545-551.

Munkres, K. D. (1979) A novel class of biochemical mutants in Neurospora crassa: Nutritional irreparable, temperatureextremity sensitive. J. Gen. Appl. Microbiol. 25, 137-144.

Munkres, K. D. (1992) Selection and analysis of superoxide dismutase mutants of Neurospora. Free Radic. Biol. Med. 13, $305-318$

Nagaike, T., Suzuki, T., Katoh, T., and Ueda, T. (2005) Human mitochondrial mRNAs are stabilized with polyadenylation regulated by mitochondria-specific poly(A) polymerase and polynucleotide phosphorylase. J. Biol. Chem. 280, 1972119727.

Nie, L., Khan, I., Misquitta, C. M., and Grover, A. K. (2004) Sarcoplasmic reticulum $\mathrm{Ca}^{2+}$ pump mRNA stability in cardiac and smooth muscle: role of poly $\mathrm{A}+$ tail length. Cell Calcium 35, 479-484.

Ninomiya, Y., Suzuki, K., Ishii, C., and Inoue, H. (2004) Highly efficient gene replacements in Neurospora strains deficient for nonhomologous end-joining. Proc. Natl. Acad. Sci. USA, 101, 12248-12253.

Ohnacker, M., Minvielle-Sebastia, L., and Keller, W. (1996) The Schizosaccharomyces pombe pla1 gene encodes a poly(A) polymerase and can functionally replace its Saccharomyces cerevisiae homologue. Nucleic Acids Res. 24, 2585-2591.

Onai, K., Katagiri, S., Akiyama, M., and Nakashima, H. (1998) Mutation of the gene for the second-largest subunit of RNA polymerase I prolongs the period length of the circadian conidiation rhythm in Neurospora crassa. Mol. Gen. Genet. 259, 264-271.

Orbach, M. J., and Sachs, M. S. (1991) The Orbach / Sachs cosmid library of $N$. crassa DNA sequences (pMOcosX). Fungal Genet. Newsl. 38, 97.

Perkins, D. D., Radford, A., and Sachs, M. S. (2001) The Neurospora Compendium. Chromosomal Loci, Academic Press, California.

Sakai, W., Ishii, C., and Inoue, H. (2002) The upr-1 gene encodes a catalytic subunit of the DNA polymerase zeta which is involved in damage-induced mutagenesis in Neurospora crassa. Mol. Genet. Genom. 267, 401-408.

Sambrook, J., Fritsch, E. F., and Maniatis, T. M. (1989) Molecular Cloning: A Laboratory Manual, 2nd ed., Cold Spring Harbor Laboratory Press, New York.

Schroeder, A. L. (1988) Use of Neurospora to study DNA repair. In "DNA Repair: a Laboratory Manual of Research Procedures" (eds.: E. C. Friedberg, and P. C. Hanawalt), Vol. 3, pp. 77-98. Marcel Dekker, Inc., New York.

Selker, E. U., Cambareri, E. B., Jensen, B. C., and Haack, K. R. (1987) Rearrangement of duplicated DNA in specialized cells of Neurospora. Cell 51, 741-752.

Shapiro, R. A., Herrick, D., Manrow, R. E., Blinder, D., and Jacobson, A. (1988) Determinants of mRNA stability in Dictyostelium discoideum amoebae: differences in poly(A) tail length, ribosome loading, and mRNA size cannot account for the heterogeneity of mRNA decay rates. Mol. Cell Biol. 8, 1957-1969.

Smith, M. L., Hubbard, S. P., Jacobson, D. J., Micali, O. C., and Glass, N. L. (2000) An osmotic-remedial, temperature-sensitive mutation in the allosteric activity site of ribonucleotide reductase in Neurospora crassa. Mol. Gen. Genet. 262, 1022-1035.

Tamaru, H., and Inoue, H. (1989) Isolation and characterization of a laccase-derepressed mutant of Neurospora crassa. J. Bacteriol. 171, 6288-6293

Tomita, H., Soshi, T., and Inoue, H. (1993) The Neurospora uvs-2 gene encodes a protein which has homology to yeast $R A D 18$, with unique zinc finger motifs. Mol. Gen. Genet. 238, 225-233.

Wahle, E. (1991) A novel poly(A)-binding protein acts as a specificity factor in the second phase of messenger RNA polyadenylation. Cell 66, 759-768 (Erratum in: Cell 1991, 67, 639).

Westergarrd, M., and Mitchell, H. K. (1947) Neurospora V. A synthetic medium favoring sexual reproduction. Am. J. Bot. 34, 573-577.

Zhelkovsky, A. M., Kessler, M. M., and Moore, C. L. (1995) Structure-function relationships in the Saccharomyces cerevisiae poly(A) polymerase. Identification of a novel RNA binding site and a domain that interacts with specificity factor(s). J. Biol. Chem. 270, 26715-26720. 